\title{
Klasifikasi Tingkat Kemurnian Bahan Bakar Minyak Berdasarkan Cepat Rambat Gelombang Menggunakan Algoritma K-Nearest Neighbor
}

\author{
Rangga Pujianto Wijaya*1, Abdul Rouf ${ }^{2}$, Tri Wahyu Supardi ${ }^{3}$ \\ ${ }^{1}$ Program Studi Elektronika dan Instrumentasi, FMIPA, UGM, Yogyakarta, Indonesia \\ ${ }^{2,3}$ Departemen Ilmu Komputer dan Elektronika, FMIPA UGM, Yogyakarta, Indonesia \\ e-mail: *11 rangga.pujianto.w@mail.ugm.ac.id, ${ }^{2}$ rouf@ugm.ac.id, ${ }^{3}$ twsupardi@ugm.ac.id
}

\begin{abstract}
Abstrak
Kebutuhan bahan bakar minyak terus bertambah seiring dengan bertambahnya jumlah penduduk, jumlah kendaraan dan jumlah industri. Adanya peningkatan kebutuhan bahan bakar minyak ini dimanfaatkan oleh sebagian orang untuk mencari keuntungan dengan menjual bahan bakar minyak campuran dengan harga yang sama yang telah ditetapkan oleh pemerintah. Tujuan penelitian ini adalah membuat purwarupa alat yang mampu mengkarakterisasi jenis bahan bakar minyak serta membuat sistem klasifikasi guna mengetahui tingkat kemurnian bahan bakar minyak dengan gelombang ultrasonik $40 \mathrm{kHz}$ berdasarkan parameter cepat rambat gelombang menggunakan algoritma K-Nearest Neighbor (KNN).

Alat ini bekerja dengan menggunakan gelombang ultrasonik $40 \mathrm{kHz}$ yang dihubungkan pada transmitter ultrasonik. Gelombang yang dirambatkan akan diterima oleh receiver ultrasonik. Gelombang yang diterima receiver akan dikuatkan dan dihubungkan dengan rangkaian komparator sehingga dapat diproses oleh mikrokontroler. Data yang diperoleh menggunakan alat ini adalah waktu tempuh gelombang, cepat rambat gelombang, massa jenis dan atenuasi. Data yang digunakan untuk sistem klasifikasi menggunakan algoritma KNN adalah cepat rambat gelombang.

Klasifikasi menggunakan algoritma KNN dapat mengidentifikasi tingkat kemurnian bahan bakar berdasarkan parameter cepat rambat gelombang yang diperoleh dari alat ukur gelombang ultrasonik dengan akurasi sebesar 72,50\%. Kecepatan rambat gelombang yang diukur menggunakan gelombang ultrasonik berbanding lurus dengan kecepatan yang sebenarnya dengan persentase penyimpangan terbesar yaitu 0,34\%.
\end{abstract}

Kata kunci - gelombang ultrasonik, K-Nearest Neighbor, cepat rambat gelombang, bahan bakar minyak

\begin{abstract}
The need for fuel oil has increased along with the increase of population, the number of vehicles and industries. An increase in demand for fuel oil is used by some people to make a profit by selling mixed fuel oil at the same price as the price set by the government. The purpose of this study is to create a prototype device that can characterize the type of fuel oil and create a classification system to determine the level of fuel purity with $40 \mathrm{kHz}$ ultrasonic waves based on the parameters of wave velocity using the K-Nearest Neighbor (KNN) algorithm.
\end{abstract}

This device works by using a $40 \mathrm{kHz}$ ultrasonic wave that is connected to an ultrasonic transmitter. The propagated wave will be received by the ultrasonic receiver. The wave received by the receiver will be amplified and connected to the comparator circuit so that it can be processed by a microcontroller. Data obtained using this tool are wave travel time, wave

Received September 16 ${ }^{\text {th }}, 2019 ;$ Revised October $24^{\text {th }}, 2019 ;$ Accepted October $30^{\text {th }}, 2019$ 
velocity, density, and attenuation. The data used for classification systems using the KNN algorithm is wave velocity.

Classification using the KNN algorithm can identify the level of fuel purity based on the parameters of the wave velocity obtained from ultrasonic wave gauges with an accuracy of $72.50 \%$. Wave velocity which is measured using ultrasonic waves is directly proportional to the actual speed with the largest percentage of deviations that is $0.34 \%$.

Keywords - ultrasonic waves, K-Nearest Neighbor, wave velocity, fuel oil

\section{PENDAHULUAN}

Bahan bakar minyak adalah sumber energi yang paling banyak digunakan di dunia, termasuk Indonesia [1] . Kebutuhan bahan bakar minyak terus bertambah seiring dengan bertambahnya jumlah penduduk, kendaraan bermotor dan industri. Adanya peningkatan kebutuhan akan bahan bakar minyak ini dimanfaatkan oleh sebagian orang untuk mencari keuntungan dengan menjual bahan bakar minyak campuran dengan harga yang sama yang telah ditetapkan oleh pemerintah. Semakin banyak bahan campuran yang dimasukkan ke dalam bahan bakar, maka penurunan nilai kalor bakar akan semakin besar [2]. Keadaan tersebut dapat menurunkan kinerja dan merusak mesin. Mudahnya meracik BBM oplosan menjadi salah satu faktor maraknya praktik pengoplosan di Indonesia saat ini. Secara kasat mata, bahan bakar murni masih sulit dibedakan dengan bahan bakar campuran.

Solusi untuk menyelesaikan permasalahan tercampurnya suatu bahan bakar yang mengakibatkan bahan bakar tersebut menjadi tidak murni yaitu mengklasifikasikan setiap jenis bahan bakar untuk mengetahui tingkat kemurniannya. Berdasarkan uraian permasalahan diatas, maka peneliti melakukan penelitian mengenai klasifikasi bahan bakar untuk mengetahui tingkat kemurnian bahan bakar minyak. Alat ini bekerja dengan menggunakan gelombang ultrasonik untuk mengkarakterisasi setiap jenis bahan bakar. Metode karakterisasi yang dilakukan bertujuan untuk menentukan nilai atenuasi, waktu tempuh gelombang, cepat rambat gelombang serta massa jenis bahan bakar menggunakan sensor ultrasonik. Karakteristik yang diperoleh dari pengukuran gelombang ultrasonik kemudian diklasifikasikan menggunakan algoritma $K$ Nearest Neighbor (KNN) untuk mengetahui tingkat kemurnian bahan bakar.

Algoritma KNN dipilih karena algoritma ini sederhana dan mudah dipelajari, tahan terhadap data pelatihan yang memiliki noise, efektif jika data pelatihan besar, dan proses pelatihan data yang sangat cepat [3]-[6]. Selain itu, algoritma KNN merupakan salah satu algoritma terbaik dalam melakukan klasifikasi data mining [7].

Untuk mengetahui karakteristik suatu bahan bakar diperlukan suatu metode nondestructive yang kuat dan akurat, sensor ultrasonik menjadi pilihan untuk melakukan penelitian ini [8]. Metode menggunakan sensor ultrasonik memiliki tingkat penetrasi yang kuat yang kemudian membuat sampel uji tidak akan rusak sehingga akan menghasilkan nilai keluaran yang baik dan dapat memproses hasilnya dengan cepat.

\section{METODE PENELITIAN}

\subsection{Analisis Sistem}

Pada penelitian ini, sistem dirancang untuk dapat mengkarakterisasi dan mengklasifikasikan tingkat kemurnian bahan bakar minyak. Karakterisasi dilakukan dengan menggunakan sensor ultrasonik. Parameter yang diukur adalah waktu tempuh gelombang, cepat rambat gelombang, massa jenis, dan atenuasi. Klasifikasi tingkat kemurnian bahan bakar dilakukan setelah mendapatkan parameter yang dihasilkan oleh alat ukur gelombang ultrasonik dengan menggunakan algoritma K-Nearest Neighbor. Atenuasi dapat dihitung dengan 
menggunakan persamaan (1) dimana $v_{0}$ adalah tegangan pada transmitter dan $v$ adalah tegangan pada receiver ultrasonik.

$$
A t t=20 \log 10 v_{0} / v
$$

Kecepatan rambat gelombang pada tiap objek berbeda-beda. Hal ini disebabkan oleh massa jenis dan modulus bulk yang dimiliki tiap objek bahan bakar berbeda. Nilai modulus bulk diacu dari penelitian Neutrium, yaitu pedoman engineering toolbox dan penelitian pencarian nilai modulus bulk. Nilai kecepatan yang sebenarnya dihitung dengan menggunakan persamaan (2), dimana B adalah modulus bulk $\left(\mathrm{N} / \mathrm{m}^{2}\right)$ dan $\rho$ adalah massa jenis $\left(\mathrm{kg} / \mathrm{m}^{3}\right)$. Nilai kecepatan ini akan digunakan sebagai pembanding dengan nilai kecepatan yang diukur menggunakan gelombang ultrasonik.

$$
v=\sqrt{\frac{B}{\rho}}
$$

Pengukuran diawali dengan mengukur massa jenis menggunakan alat konvensional yaitu berupa gelas ukur dan timbangan kimia untuk mengetahui massa dan volume setiap bahan bakar yang akan diuji. Kemudian massa jenis akan diukur menggunakan cepat rambat gelombang ultrasonik.

Massa jenis diperoleh dari konversi hasil cepat rambat gelombang ultrasonik yang dirambatkan secara langsung dari transmitter ke receiver. Setiap jenis bahan bakar minyak memiliki massa jenis yang berbeda-beda, faktor inilah yang menyebabkan cepat rambat gelombang ultrasonik dapat berbeda-beda. Gelombang dirambatkan melalui medium cairan, sehingga sensor ultrasonik yang digunakan haruslah tahan terhadap cairan (waterproof). Besarnya frekuensi gelombang ultrasonik adalah sebesar $40 \mathrm{kHz}$ agar bisa menembus medium bahan bakar minyak [9], [10]. Mikrokontroler menginstruksikan pembangkit gelombang untuk membangkitkan gelombang sinusoidal $40 \mathrm{kHz}$ yang dihubungkan dengan transmitter ultrasonik. Gelombang hasil pancaran transmitter ultrasonik akan diterima oleh receiver ultrasonik. Sinyal yang diterima di receiver sangatlah kecil, sehingga butuh rangkaian penguat sinyal. Hasil dari receiver yang telah dikuatkan diteruskan ke rangkaian komparator agar dapat dideteksi oleh mikrokontroler.

Parameter cepat rambat gelombang digunakan untuk mengklasifikasikan tingkat kemurnian bahan bakar minyak dengan algoritma K-Nearest Neighbor (KNN). Klasifikasi menggunakan KNN bertujuan untuk mengetahui tingkat kemurnian bahan bakar minyak berdasarkan jumlah tetangga terdekat dari suatu data [4], [11]-[13]. Terdapat 200 data yang telah didapat menggunakan alat ukur sensor ultrasonik. Data ini akan dibagi menjadi data latih dan data uji untuk membentuk model klasifikasi. Dalam KNN perlu menetapkan nilai k yaitu jumlah tetangga terdekat, kemudian menghitung jarak ketetanggaan (similarity measure) masing-masing objek terhadap data uji yang diberikan [5], [11], [14]. Tahap selanjutnya adalah mengurutkan objek-objek tersebut kedalam kelompok yang mempunyai jarak terkecil sampai terbesar, kemudian mengumpulkan kategori klasifikasi [15]. Label suatu data baru dapat diprediksi dengan menggunakan kategori K-Nearest Neighbor yang paling mayoritas [4], [11], [15].

\subsection{Rancangan Penguat Sinyal Pada Receiver Ultrasonik}

Gelombang yang dirambatkan melalui medium bahan bakar minyak mengalami pelemahan sehingga receiver ultrasonik menerima gelombang dengan orde mili volt. Zat cair mempunyai kerapatan zat per volume yang lebih tinggi dari udara, sehingga untuk mengirim gelombang ultrasonik dari transmitter dan agar gelombang ultrasonik dapat diterima oleh receiver diperlukan penguatan gelombang ultrasonic [9]. 


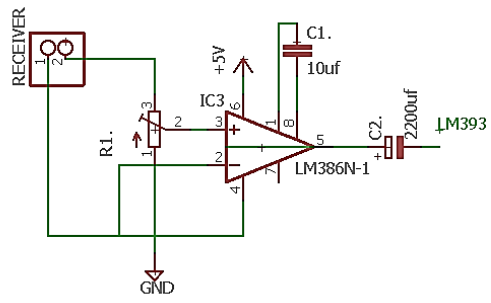

Gambar 1 Rangkaian Penguat Sinyal

Komponen yang digunakan untuk menguatkan tegangan adalah IC LM386 dengan penguatan sesebesar 200 kali. Penguatan ini dilakukan agar tegangan dapat terbaca oleh komparator dan selanjutnya diteruskan pada mikrokontroler Teensy 3.2. Rangkaian penguat sinyal ditunjukkan pada Gambar 1.

\subsection{Rancangan Rangkaian Komparator}

IC LM393 digunakan untuk membandingkan dua tegangan yang dihubungkan pada input positif dan input negatif. Input positif dihubungkan dengan output penguat sinyal receiver dan input negatif dihubungkan dengan potensiometer yang berfungsi sebagai tegangan referensi dan juga dihubungkan pada pin analog A0 Teensy 3.2. Output komparator dihubungkan pada pin digital 16 Teensy 3.2. Apabila input positif lebih besar dari input negatif, maka tegangan output menjadi $5 \mathrm{~V}$. Apabila input positif lebih kecil dari input negatif, maka tegangan output menjadi 0 V. Rangkaian komparator ditunjukkan pada Gambar 2.

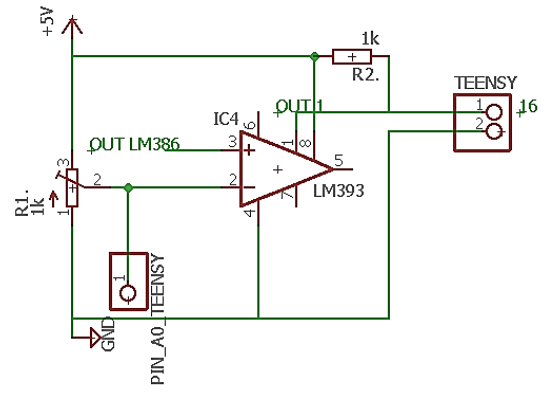

Gambar 2 Rancangan Rangkaian Komparator

\section{$2.4 \quad$ Rancangan Objek Uji}

Objek yang diuji pada penelitian ini menggunakan bahan bakar dari PT Pertamina yaitu Pertalite, Pertamina Dex, dan Kerosin. Pengujian dilakukan dengan cara menempatkan transmitter dan receiver ultrasonik secara berhadap-hadapan. Rancangan wadah uji ditunjukkan pada Gambar 3. Wadah ini memiliki panjang $20 \mathrm{~cm}$, lebar $3,5 \mathrm{~cm}$, dan tinggi $5 \mathrm{~cm}$. Sensor ultrasonik dipasang pada kedua sisi wadah dengan diameter $1,6 \mathrm{~cm}$ dan Panjang 0,5 cm, sehingga jarak antara transmitter dan receiver yaitu sebesar $19 \mathrm{~cm}$. Volume yang bisa masuk ke dalam wadah adalah sebesar $350 \mathrm{~cm} 3$, tetapi peneliti membatasi volume yang masuk kedalam wadah sebesar $130 \mathrm{~cm} 3$ untuk meminimalisir noise dan menghemat biaya penelitian.

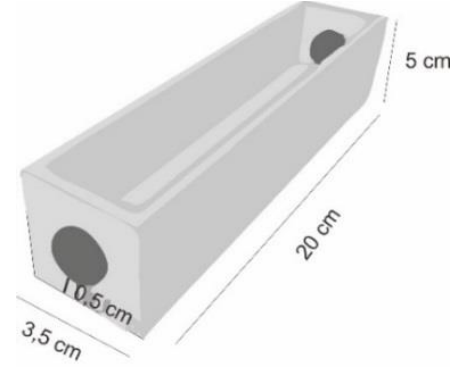

Gambar 3 Rancangan Wadah Objek Uji 


\subsection{Rancangan Algoritma pada Alat Ukur Gelombang Ultrasonik}

Rancangan ini digunakan untuk menghitung waktu tempuh gelombang melewati bahan bakar minyak kemudian dikonversi menjadi cepat rambat gelombang dan massa jenis. Untuk mendapat satu data pengukuran dilakukan pencuplikan data sebanyak 100 kali, kemudian diambil nilai terkecil dari pengukuran dan dirata-rata. Bentuk diagram alir pengukuran pada alat ukur gelombang ultrasonik ditunjukkan pada Gambar 4.

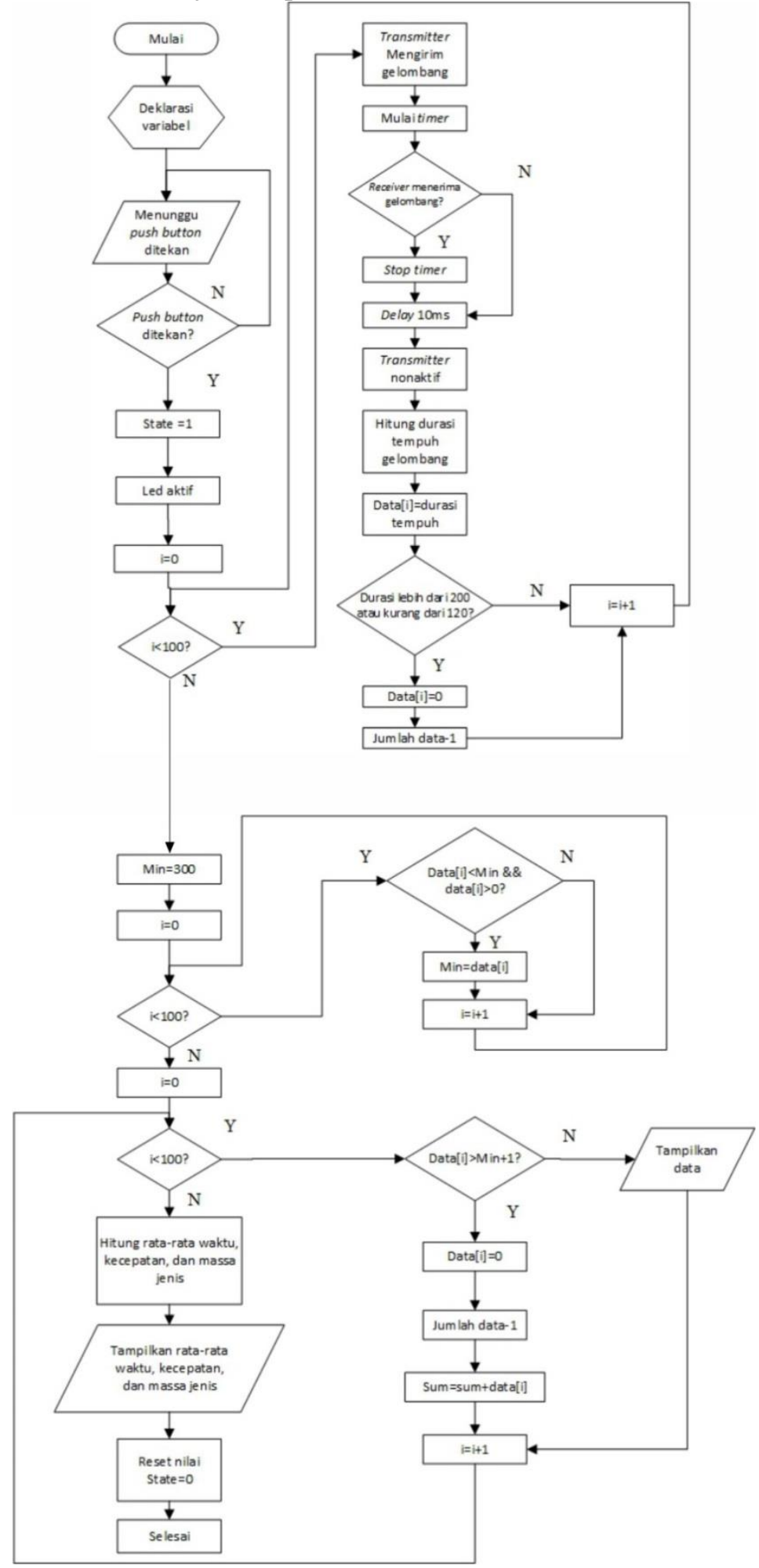

Gambar 4 Diagram Alir Pengukuran pada Alat Ukur Gelombang Ultrasonik 


\subsection{Rancangan Algoritma K-Nearest Neighbor}

Klasifikasi tingkat kemurnian bahan bakar dilakukan menggunakan metode $K$-Nearest Neighbor. Metode ini merupakan metode pengklasifikasikan suatu objek berdasarkan data pembelajaran yang jaraknya paling dekat dengan objek tersebut [7]. Tujuan dari algoritma ini adalah untuk mengklasifikasikan tingkat kemurnian bahan bakar minyak berdasarkan atribut dan training sample yang diperoleh dari alat ukur sensor ultrasonik, kemudian data tersebut disimpan dalam format csv [4], [14]. Pengklasifikasian ini menghasilkan 20 kelas yaitu Pertalite $100 \%$, Pertalite $90 \%$, Pertalite $80 \%$, Pertalite $70 \%$, Pertalite $60 \%$, Pertalite $50 \%$, Pertalite $40 \%$, Pertalite 30\%, Pertalite 20\%, Pertalite 10\%, Pertamina Dex 100\%, , Pertamina Dex 90\%, Pertamina Dex 80\%, Pertamina Dex 70\%, Pertamina Dex 60\%, Pertamina Dex 50\%, Pertamina Dex 40\%, Pertamina Dex 30\%, Pertamina Dex 20\%, dan Pertamina Dex 10\%. Klasifikasi ini menggunakan euclidean distance untuk menentukan kelas suatu objek [3], [5], [11], [16]. Diagram alir proses klasifikasi ditunjukkan pada Gambar 5. Klasifikasi ini menggunakan bahasa pemrograman python dan jupyter notebook sebagai IDE.

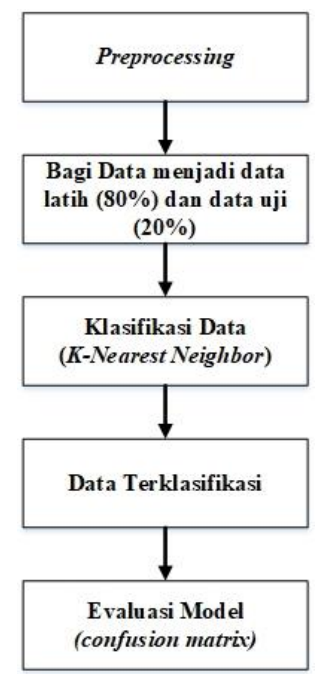

Gambar 5 Diagram Alir Klasifikasi

\subsection{Implementasi Perangkat Keras}

Perangkat keras yang digunakan pada penelitian ini adalah catu daya, regulator tegangan 7805, transistor NPN 2N3904, transistor PNP 2N3906, IC LM393, transduser ultrasonik waterproof, mikrokontroler Teensy 3.2, modul XR2206, IC LM386, osiloskop dan LCD 16x2. Sistem ini menggunakan adaptor AC-DC 12 V 1 A sebagai sumber daya yang dapat menghasilkan tegangan konstan $12 \mathrm{~V}$ yang kemudian dihubungkan kepada pembangkit gelombang XR2206. Tegangan dari adaptor juga dihubungkan dengan regulator tegangan LM7805 agar dapat menghasilkan tegangan konstan $5 \mathrm{~V}$ yang akan digunakan untuk mengoperasikan mikrokontroler Teensy 3.2, IC LM386 dan IC LM 393. Perangkat keras yang telah dipasang pada printed circuit board (PCB) ditunjukkan pada Gambar 6

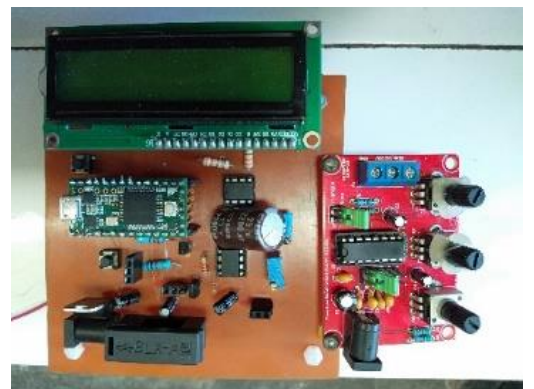

Gambar 6 Hasil Pemasangan Komponen pada PCB

IJEIS Vol. 9, No. 2, October 2019: $161-172$ 


\section{HASIL DAN PEMBAHASAN}

\subsection{Pengukuran Atenuasi}

Pengukuran atenuasi dilakukan dengan mengamati besar tegangan pada receiver ultrasonik dan tegangan pada transmitter ultrasonik. Perhitungan atenuasi mengacu pada persamaan (1). Perbandingan antara atenuasi bahan bakar dengan massa jenis bahan bakar ditunjukkan pada Tabel 1. Jika dikorelasikan atenuasi objek dengan massa jenis bahan bakar maka tidak ada korelasi yang terlihat atau tidak ada kecocokan seperti yang terlihat pada Gambar 7. Atenuasi objek memiliki korelasi yang kuat dengan massa jenis bahan bakar murni yaitu Pertalite murni, Kerosin, dan Pertamina Dex murni. Seperti yang telihat pada Gambar 8.

Tabel 1 Perbandingan Atenuasi Objek dengan Massa Jenis Bahan Bakar

\begin{tabular}{|l|l|c|c|}
\hline No. & Objek & Atenuasi objek $(\mathrm{dB})$ & Massa Jenis $(\mathrm{kg} / \mathrm{m} 3)$ \\
\hline 1 & Pertamina Dex 100\% & 25,07 & 835 \\
\hline 2 & Pertamina Dex 90\% & 24,42 & 830 \\
\hline 3 & Pertamina Dex 80\% & 23,69 & 825 \\
\hline 4 & Pertamina Dex 70\% & 20,85 & 820 \\
\hline 5 & Pertamina Dex 60\% & 20,85 & 815 \\
\hline 6 & Pertamina Dex 50\% & 20,45 & 810 \\
\hline 7 & Pertamina Dex 40\% & 19,26 & 805 \\
\hline 8 & Pertamina Dex 30\% & 18,78 & 800 \\
\hline 9 & Pertamina Dex 20\% & 17,56 & 795 \\
\hline 10 & Pertamina Dex 10\% & 19,76 & 790 \\
\hline 11 & Kerosin 100\% & 24,54 & 785 \\
\hline 12 & Pertalite 10\% & 21,19 & 780 \\
\hline 13 & Pertalite 20\% & 29,37 & 775 \\
\hline 14 & Pertalite 30\% & 29,15 & 770 \\
\hline 15 & Pertalite 40\% & 26,08 & 765 \\
\hline 16 & Pertalite 50\% & 19,76 & 760 \\
\hline 17 & Pertalite $60 \%$ & 26,39 & 755 \\
\hline 18 & Pertalite 70\% & 26,39 & 750 \\
\hline 19 & Pertalite $80 \%$ & 23,81 & 745 \\
\hline 20 & Pertalite 90\% & 24,74 & 740 \\
\hline 21 & Pertalite $100 \%$ & 23,81 & 735 \\
\hline
\end{tabular}

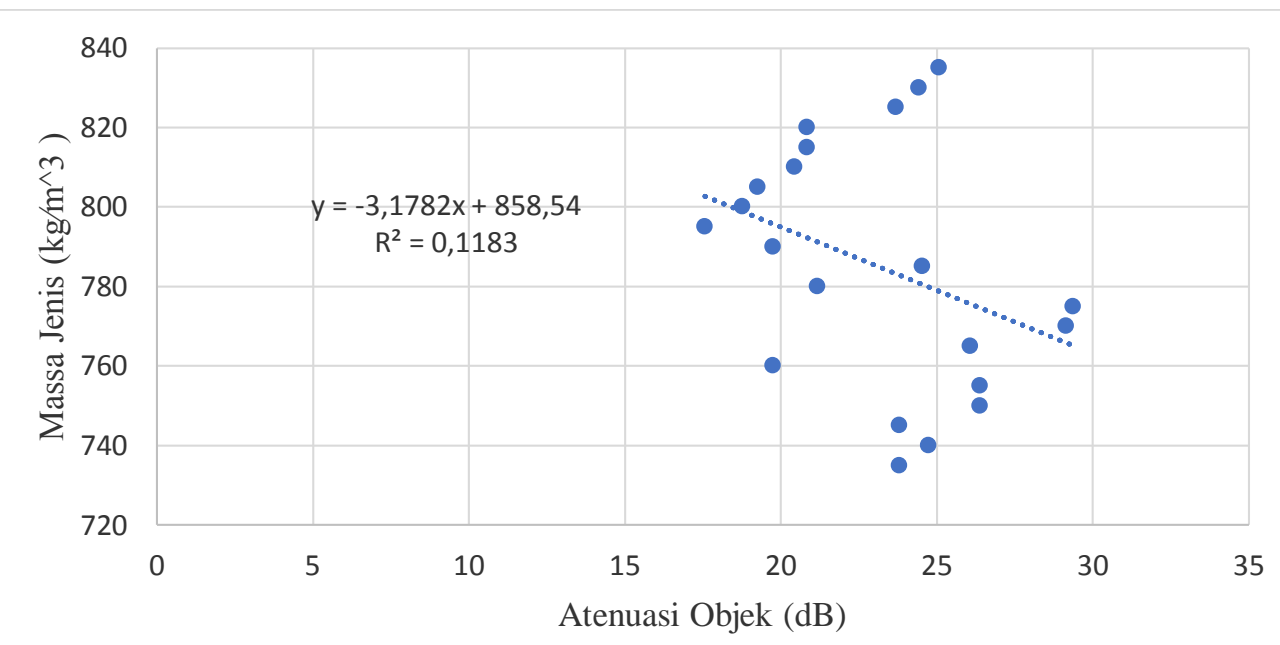

Gambar 7 Scatter Plot Korelasi Atenuasi Objek dengan Massa Jenis Bahan Bakar 


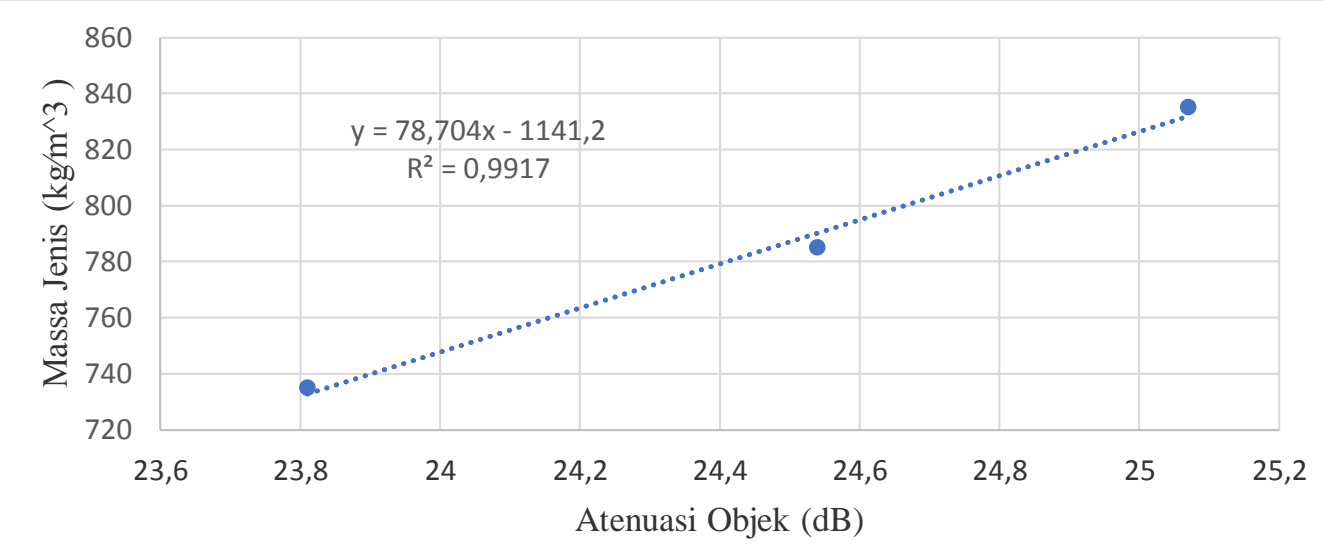

Gambar 8 Scatter Plot Korelasi Atenuasi Objek dengan Massa Jenis Bahan Bakar Murni

\subsection{Pengukuran Kecepatan Gelombang}

Hasil yang diperoleh menggunakan sensor ultrasonik sedikit berbeda dengan kecepatan yang seharusnya, oleh karenanya dibutuhkan kalibrasi nilai kecepatan. Fungsi trendline pada microsoft excel digunakan untuk mengkalibrasi nilai kecepatan pada alat agar nilai kecepatan yang dihasilkan alat ukur gelombang ultrasonik bisa mendekati nilai kecepatan yang sebenarnya. Gambar 9 menunjukkan scatter plot kecepatan yang terukur dengan tolok ukur kecepatan. Persamaan (3) diperoleh untuk mengkalibrasi nilai kecepatan sensor ultrasonik berdasarkan scatter plot yang ditunjukkan pada Gambar 9. Nilai tolok ukur kecepatan, nilai kecepatan sebelum dan setelah kalibrasi ditunjukkan pada Tabel 2. Nilai kecepatan gelombang ultrasonik pada objek bahan bakar minyak berbanding lurus dengan nilai tolok ukur kecepatan yang sebenarnya dengan nilai penyimpangan terbesar yaitu $0,338 \%$.

$y=0,1563 x+1176$

Tabel 2 Pengukuran Kecepatan Gelombang

\begin{tabular}{|l|l|l|c|c|c|c|}
\hline No. & Objek & $\begin{array}{c}\text { Modulus } \\
\left.\text { Bulk (N/m }{ }^{2}\right)\end{array}$ & $\begin{array}{c}\text { Massa } \\
\text { Jenis } \\
\left(\mathrm{kg} / \mathrm{m}^{3}\right)\end{array}$ & $\begin{array}{c}\text { Tolok } \\
\text { Ukur } \\
\text { Kecepatan } \\
(\mathrm{m} / \mathrm{s})\end{array}$ & $\begin{array}{c}\text { Kecepatan } \\
\text { Sebelum } \\
\text { Kalibrasi } \\
(\mathrm{m} / \mathrm{s})\end{array}$ & $\begin{array}{c}\text { Kecepatan } \\
\text { Setelah } \\
\text { Kalibrasi } \\
(\mathrm{m} / \mathrm{s})\end{array}$ \\
\hline 1 & Pertamina Dex 100\% & $15,45 \times 10^{8}$ & 835 & 1360,26 & 1173,24 & 1359,41 \\
\hline 2 & Pertamina Dex 90\% & $15,34 \times 10^{8}$ & 830 & 1359,70 & 1173,48 & 1359,21 \\
\hline 3 & Pertamina Dex 80\% & $15,24 \times 10^{8}$ & 825 & 1359,14 & 1172,14 & 1358,50 \\
\hline 4 & Pertamina Dex 70\% & $15,13 \times 10^{8}$ & 820 & 1358,58 & 1167,61 & 1358,30 \\
\hline 5 & Pertamina Dex 60\% & $15,03 \times 10^{8}$ & 815 & 1358,00 & 1166,37 & 1357,25 \\
\hline 6 & Pertamina Dex 50\% & $14,92 \times 10^{8}$ & 810 & 1357,42 & 1159,63 & 1357,26 \\
\hline 7 & Pertamina Dex 40\% & $14,82 \times 10^{8}$ & 805 & 1356,83 & 1155,68 & 1356,63 \\
\hline 8 & Pertamina Dex 30\% & $14,71 \times 10^{8}$ & 800 & 1356,24 & 1153,86 & 1356,35 \\
\hline 9 & Pertamina Dex 20\% & $14,61 \times 10^{8}$ & 795 & 1355,63 & 1149,18 & 1355,62 \\
\hline 10 & Pertamina Dex 10\% & $14,50 \times 10^{8}$ & 790 & 1355,02 & 1147,79 & 1355,40 \\
\hline 11 & Kerosin 100\% & $14,40 \times 10^{8}$ & 785 & 1354,40 & 1147,24 & 1355,31 \\
\hline 12 & Pertalite 10\% & $14,28 \times 10^{8}$ & 780 & 1353,06 & 1138,71 & 1353,98 \\
\hline 13 & Pertalite 20\% & $14,16 \times 10^{8}$ & 775 & 1351,70 & 1125,49 & 1351,91 \\
\hline 14 & Pertalite 30\% & $14,04 \times 10^{8}$ & 770 & 1350,32 & 1117,33 & 1350,64 \\
\hline 15 & Pertalite 40\% & $13,92 \times 10^{8}$ & 765 & 1348,93 & 1104,75 & 1348,67 \\
\hline 16 & Pertalite 50\% & $13,80 \times 10^{8}$ & 760 & 1347,51 & 1095,93 & 1347,29 \\
\hline & & & & & & \\
\hline
\end{tabular}

IJEIS Vol. 9, No. 2, October 2019: 161 - 172 
Tabel 2 Pengukuran Kecepatan Gelombang (Lanjutan)

\begin{tabular}{|l|l|c|c|c|c|c|}
\hline No. & Objek & $\begin{array}{c}\text { Modulus } \\
\text { Bulk }\left(\mathrm{N} / \mathrm{m}^{2}\right)\end{array}$ & $\begin{array}{c}\text { Massa } \\
\text { Jenis } \\
\left(\mathrm{kg} / \mathrm{m}^{3}\right)\end{array}$ & $\begin{array}{c}\text { Tolok } \\
\text { Ukur } \\
\text { Kecepatan } \\
(\mathrm{m} / \mathrm{s})\end{array}$ & $\begin{array}{c}\text { Kecepatan } \\
\text { Sebelum } \\
\text { Kalibrasi } \\
(\mathrm{m} / \mathrm{s})\end{array}$ & $\begin{array}{c}\text { Kecepatan } \\
\text { Setelah } \\
\text { Kalibrasi } \\
(\mathrm{m} / \mathrm{s})\end{array}$ \\
\hline 17 & Pertalite $60 \%$ & $13,68 \times 10^{8}$ & 755 & 1346,08 & 1079,94 & 1344,80 \\
\hline 18 & Pertalite $70 \%$ & $13,56 \times 10^{8}$ & 750 & 1344,62 & 1069,24 & 1343,12 \\
\hline 19 & Pertalite $80 \%$ & $13,44 \times 10^{8}$ & 745 & 1343,14 & 1068,24 & 1342,97 \\
\hline 20 & Pertalite $90 \%$ & $13,32 \times 10^{8}$ & 740 & 1341,64 & 1064,97 & 1342,45 \\
\hline 21 & Pertalite $100 \%$ & $13,20 \times 10^{8}$ & 735 & 1340,12 & 1059,58 & 1341,61 \\
\hline
\end{tabular}

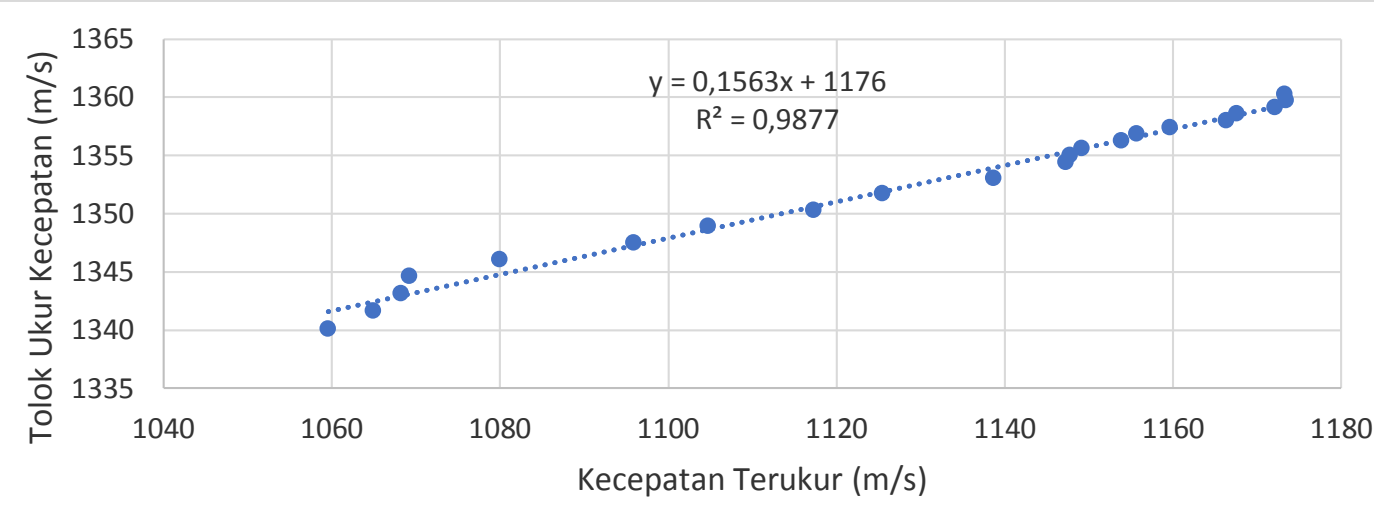

Gambar 9 Scatter Plot Perbandingan Kecepatan Terukur dengan Tolok Ukur Kecepatan

\subsection{Pengukuran Massa Jenis}

Nilai massa jenis yang diukur menggunakan gelombang ultrasonik hampir sama dengan nilai massa jenis yang diukur menggunakan alat konvensional. Nilai massa jenis dengan menggunakan gelombang ultrasonik berbanding lurus dengan massa jenis bahan bakar minyak yang sebenarnya. rata-rata persentase penyimpangan nilai massa jenis adalah $0,121 \%$ dan ratarata persentase akurasi nilai massa jenis adalah 99,879\%. Persentase penyimpangan terbesar adalah sebesar $0,674 \%$. Tabel 3 menunjukkan nilai pengukuran massa jenis dengan alat konvensional dan nilai massa jenis dengan gelombang ultrasonik.

Tabel 3 Pengukuran Massa Jenis

\begin{tabular}{|l|l|c|c|}
\hline No. & Objek & $\begin{array}{c}\text { Nilai Massa Jenis dengan } \\
\text { Alat Konvensional } \\
\left(\mathrm{kg} / \mathrm{m}^{3}\right)\end{array}$ & $\begin{array}{c}\text { Nilai Massa Jenis dengan } \\
\text { Gelombang Ultrasonik } \\
\left(\mathrm{kg} / \mathrm{m}^{3}\right)\end{array}$ \\
\hline 1 & Pertamina Dex 100\% & 835 & 836,04 \\
\hline 2 & Pertamina Dex 90\% & 830 & 830,34 \\
\hline 3 & Pertamina Dex 80\% & 825 & 825,78 \\
\hline 4 & Pertamina Dex 70\% & 820 & 820,06 \\
\hline 5 & Pertamina Dex 60\% & 815 & 815,91 \\
\hline 6 & Pertamina Dex 50\% & 810 & 809,92 \\
\hline 7 & Pertamina Dex 40\% & 805 & 805,24 \\
\hline 8 & Pertamina Dex 30\% & 800 & 799,60 \\
\hline 9 & Pertamina Dex 20\% & 795 & 795,02 \\
\hline 10 & Pertamina Dex 10\% & 790 & 789,28 \\
\hline 11 & Kerosin 100\% & 785 & 785,07 \\
\hline 12 & Pertalite 10\% & 780 & 779,80 \\
\hline
\end{tabular}


Tabel 3 Pengukuran Massa Jenis (Lanjutan)

\begin{tabular}{|l|l|l|l|}
\hline No. & Objek & $\begin{array}{l}\text { Nilai Massa Jenis dengan } \\
\text { Alat Konvensional } \\
\left(\mathrm{kg} / \mathrm{m}^{3}\right)\end{array}$ & $\begin{array}{l}\text { Nilai Massa Jenis dengan } \\
\text { Gelombang Ultrasonik } \\
\left(\mathrm{kg} / \mathrm{m}^{3}\right)\end{array}$ \\
\hline 13 & Pertalite $20 \%$ & 775 & 774,76 \\
\hline 14 & Pertalite 30\% & 770 & 768,94 \\
\hline 15 & Pertalite $40 \%$ & 765 & 764,86 \\
\hline 16 & Pertalite $50 \%$ & 760 & 760,88 \\
\hline 17 & Pertalite 60\% & 755 & 755,76 \\
\hline 18 & Pertalite $70 \%$ & 750 & 751,40 \\
\hline 19 & Pertalite $80 \%$ & 745 & 745,83 \\
\hline 20 & Pertalite $90 \%$ & 740 & 735,01 \\
\hline 21 & Pertalite $100 \%$ & 735 & 730,86 \\
\hline
\end{tabular}

3.4 Klasifikasi Jenis Bahan Bakar Minyak Menggunakan K-Nearest Neighbor (KNN)

Pengujian dilakukan dengan memvariasikan nilai $\mathrm{k}$ pada algoritma KNN untuk menentukan tingkat kemurnian bahan bakar. Pada proses klasifikasi dengan algoritma KNN, nilai $\mathrm{k}$ (jumlah tetangga terdekat) sangat berpengaruh pada nilai akurasi yang dihasilkan. Nilai $\mathrm{k}$ merupakan nilai ganjil karena penentuan kelas suatu data dilakukan menggunakan voting sehingga pengambilan nilai $\mathrm{k}$ ganjil akan mencegah terjadinya hasil voting yang seimbang. Pada penelitian ini dilakukan variasi nilai $\mathrm{k}$ dimulai dari $\mathrm{k}=1$ sampai $\mathrm{k}=11$. Confusion matrix digunakan untuk menghitung akurasi dari sistem. Tabel 4 menunjukkan confusion matrix dari setiap nilai $\mathrm{k}$ yang diuji.

Tabel 4 Akurasi pada Variasi Nilai k

\begin{tabular}{|l|l|}
\hline $\mathrm{k}$ & Akurasi \\
\hline 1 & $67,5 \%$ \\
\hline 3 & $67,5 \%$ \\
\hline 5 & $72,5 \%$ \\
\hline 7 & $67,5 \%$ \\
\hline 9 & $60,0 \%$ \\
\hline 11 & $60,0 \%$ \\
\hline
\end{tabular}

Pada Gambar 10, data yang diperoleh dari alat ukur gelombang ultrasonik memiliki nilai waktu tempuh $164,82 \mu$ s pada jarak $19 \mathrm{~cm}$ sehingga nilai cepat rambat gelombangnya adalah sebesar 1356,17 m/s. Data bahan bakar yang belum diketahui tingkat kemurniannya tersebut diproses menggunakan algoritma K-Nearest Neighbor, sehingga hasil yang diperoleh adalah Pertamina Dex dengan tingkat kemurnian 30\%, sedangkan 70\% nya merupakan bahan campuran minyak tanah (Kerosin). Berdasarkan penelitian yang telah dilakukan, algoritma $K$ Nearest Neighbor dapat memprediksi data bahan bakar minyak yang belum diketahui tingkat kemurniannya berdasarkan data pembelajaran yang jaraknya paling dekat dengan data uji.

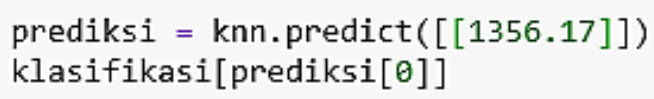

'PertaminaDex $30 \%$ '

Gambar 10 Pengujian Klasifikasi Jenis Bahan Bakar 


\section{KESIMPULAN}

Kesimpulan yang dapat diambil pada penelitian ini adalah klasifikasi menggunakan algoritma $K$-Nearest Neighbor dapat mengidentifikasi tingkat kemurnian bahan bakar minyak berdasarkan parameter cepat rambat gelombang yang diperoleh dari alat ukur gelombang ultrasonik dengan akurasi terbaik sebesar $72,50 \%$ dengan nilai $\mathrm{k}=5$. Gelombang ultrasonik dengan frekuensi $40 \mathrm{kHz}$ mampu menembus bahan bakar minyak serta dapat mengkarakterisasi jenis bahan bakar minyak dengan parameter waktu tempuh gelombang, cepat rambat gelombang, atenuasi, dan massa jenis bahan bakar minyak. Kecepatan rambat gelombang yang diukur menggunakan gelombang ultrasonik berbanding lurus dengan kecepatan yang sebenarnya dengan persentase penyimpangan terbesar yaitu $0,34 \%$. Atenuasi tidak memiliki korelasi dengan massa jenis pada setiap sampel uji, tetapi atenuasi sangat berkorelasi terhadap massa jenis bahan bakar murni. Massa jenis yang diukur menggunakan gelombang ultrasonik berbanding lurus dengan massa jenis yang sebenarnya dengan nilai persentase penyimpangan terbesar yaitu $0,67 \%$.

\section{SARAN}

Pada penelitian skripsi ini, masih terdapat beberapa hal yang perlu disempurnakan. Saran- saran yang dapat menyempurnakan penelitian skripsi ini yaitu penelitian selanjutnya dapat mengimplementasikan algoritma klasifikasi ke dalam mikrokontroler untuk mengetahui tingkat kemurnian bahan bakar.

\section{DAFTAR PUSTAKA}

[1] E. Alwi, D. S. Putra, and H. Khoiri, "Uji Penghematan Bahan Bakar Kendaraan Dengan Sistem Pembatasan Putaran Mesin," vol. 2, no. 1, pp. 47-54, 2017.

[2] I. Tazi and Sulistiana, "Uji Kalor Bakar Bahan Bakar Campuran Bioetanol Dan Minyak Goreng Bekas," J. Neutrino, vol. 3, no. 2, pp. 163-174, 2012.

[3] P. Baraldi, F. Cannarile, F. Di Maio, and E. Zio, "Hierarchical K-Nearest Neighbours Classification and Binary Differential Evolution for Fault Diagnostics of Automotive Bearings Operating Under Variable Conditions," Eng. Appl. Artif. Intell., vol. 56, pp. 113, 2016 [Online]. Available: http://dx.doi.org/10.1016/j.engappai.2016.08.011

[4] P. Müller et al., "Scent Classification by K Nearest Neighbors Using Ion-Mobility Spectrometry Measurements," Expert Syst. Appl., vol. 115, pp. 593-606, 2019.

[5] J. das C. Rodrigues, P. P. R. Filho, E. Peixoto, A. K. N, and V. H. C. de Albuquerque, "Classification of EEG Signals to Detect Alcoholism Using Machine Learning Techniques," Pattern Recognit. Lett., vol. 125, pp. 140-149, 2019.

[6] S. Mutrofin, A. Izzah, A. Kurniawardhani, and M. Masrur, "Optimasi Teknik Klasifikasi Modified K Nearest Neighbor Menggunakan Algoritma Genetika," no. September, pp. 130-134, 2014.

[7] X. Wu and V. Kumar, The Top Ten Algorithms in Data Mining. Boca Raton: Taylor \& Francis Group, 2009.

[8] M. K. K. Figueiredo, A. V. Alvarenga, and R. P. B. Costa-Félix, "Ultrasonic Attenuation and Sound Velocity Assessment for Mixtures of Gasoline and Organic Compounds," Fuel, vol. 191, pp. 170-175, 2016 [Online]. Available: http://dx.doi.org/10.1016/j.fuel.2016.11.076

[9] N. B. Prawira and A. Rouf, "Perancangan Alat Ukur Massa Jenis Zat Cair Menggunakan Cepat Rambat Gelombang Ultrasonik," IJEIS (Indonesian J. Electron. Instrum. Syst., vol. 8, no. 2, p. 143, 2018.

[10] S. Swasoko and A. Rouf, "Rancang Bangun Pembangkit Pulsa Tiga Sensor Ultrasonik 
Untuk Pendeteksi Kecacatan Beton Berbasis Mikrokontroler," IJEIS (Indonesian J. Electron. Instrum. Syst., vol. 7, no. 2, p. 197, 2017.

[11] A. Bablani, D. R. Edla, and S. Dodia, "Classification of EEG Data Using K-Nearest Neighbor Approach for Concealed Information Test," Procedia Comput. Sci., vol. 143, pp. 242-249, 2018 [Online]. Available: https://doi.org/10.1016/j.procs.2018.10.392

[12] S. Faziludeen and P. Sankaran, "ECG Beat Classification Using Evidential K -Nearest Neighbours," Procedia Comput. Sci., vol. 89, pp. 499-505, 2016 [Online]. Available: http://dx.doi.org/10.1016/j.procs.2016.06.106

[13] Z. S. Badu, "Penerapan Algoritma K-Nearest Neighbor Untuk Klasifikasi Dana Desa," 2016.

[14] L. B. Marinho, P. P. Rebouças Filho, and V. H. C. de Albuquerque, "Ultrasonic Sensor Signals and Self Organized Mapping with Nearest Neighbors for the Microstructural Characterization of Thermally-Aged Inconel 625 Alloy," Comput. Ind., vol. 107, pp. 110, 2019 [Online]. Available: https://doi.org/10.1016/j.compind.2019.01.009

[15] Y. F. Safri, R. Arifudin, and M. A. Muslim, "K-Nearest Neighbor and Naive Bayes Classifier Algorithm in Determining The Classification of Healthy Card Indonesia Giving to The Poor," Sci. J. Informatics, vol. 5, no. 1, p. 18, 2018.

[16] F. Borghesan, M. Chioua, and N. F. Thornhill, "Forecasting of Process Disturbances Using K-Nearest Neighbours, with an Application in Process Control," Comput. Chem. Eng., vol. 128, no. 675215, pp. 188-200, 2019 [Online]. Available: https://doi.org/10.1016/j.compchemeng.2019.05.009 